\title{
Development of Alternative Electrical Energy Utilizing Thermo Electric Generators (TEG) for Refrigerators
}

\author{
Anthony S. Tolentino
}

\begin{abstract}
The study aims to harness electrical energy from the wasted heat of refrigerator by using the temperature difference of the hot side surface and cold side surface. The use of Seebeck effect was applied to gather the said electrical energy. The system is composed of a charge controller to regulate the output of the thermoelectric generator as well as provide a direct current type of voltage. The energy that comes from the charge controller is stored thru a backup battery bank and will be used for the charging of the different low voltage devices like cellphones, tablets, etc. The charging time of the batteries going from zero percent charge to $100 \%$ charge depends on the output current of the TEG and also dependent on the temperature difference of the refrigerator. A current of $1.5 \mathrm{~mA}$ coming from the TEG will provide 50mins charging time for the battery. The total mean parameters for the output system are the following: mean voltage $=5.82 \mathrm{~V}$, the mean current $=0.8695 \mathrm{~mA}$, and the mean power output $=4.60165 \mathrm{~mW}$.
\end{abstract}

Keywords - alternative form of energy, thermoelectric generator, charge controller, green engineering, batteries

\section{INTRODUCTION}

\section{a) RATIONALE}

TEGPower (2013) states that electricity is not anymore a luxury but becomes a necessity in our daily lives. The source of pure energy has become scarce and there is a need for alternative use of energy. There are many types of alternative energy namely: solar, mechanical, piezoelectric, geothermal, and others.

This study aims to use thermoelectric generators (TEG) as the main component for harnessing electrical energy. Previous studies have used solar panels, mechanical turbines, and piezoelectric generators for harnessing energy. The TEG will be inserted in different parts of the appliances inside a house. The air conditioners, refrigerators, television sets and other appliances dissipates large amount of heat when used up. The heat that is wasted can be converted to an electrical energy because of this study. The solar panels that were used at the roofs of the houses generate electricity coming from the light of the sun. The TEG, on the other

Revised Manuscript Received on December 30, 2019.

* Correspondence Author

Anthony S. Tolentino*, ECE Department, Don Honorio Ventura State University, Cabambangan Bacolor, Pampanga, Philippines. Email: as.tolentino@yahoo.com

(C) The Authors. Published by Blue Eyes Intelligence Engineering and Sciences Publication (BEIESP). This is an open access article under the CC BY-NC-ND license (http://creativecommons.org/licenses/by-nc-nd/4.0/) hand, converts the heat of the sun to electricity. If combining both solar and TEG in harnessing energy, it would create a larger amount of electrical energy. Given also the fact that the Philippines is a hot weathered country and it would be more efficient to use the TEG in the country. The study will also give a comparison between the energy that can be saved by using the TEG and using the ordinary electrical source that we have.

\section{OBJECTIVES}

The main objective of this study is to harness the electrical energy that come from the heat of refrigerators.

Specific objectives are:

1. To use TEG and insert it to refrigerators to gather electrical energy

2. To utilize a DC-DC converter or DC-AC inverter for the input coming from the TEG

3. To use a secondary cell battery for storage of the said harnessed electrical energy

4. To apply the harnessed electrical energy for different purposes

\section{METHODOLOGY}

The study will utilize applied research. Applied research refers to scientific study and research that seeks practical problems. Applied research is used to find solutions to everyday problems, cure illness, and develop innovative technologies, rather than to acquire knowledge for knowledge's sake. Research and experimentation has been conducted on different methods of generating power, and recently the use of TEG has been popular since energy is easily harnessed from the heat that is coming from the material in which the TEG has been applied. The study will implement certain tests, experiments, and comparisons among the different characteristics of the TEG.

\section{DATA AND RESULTS}

This phase covers the operation and the different test used during the operation. It is composed of the Temperature Testing, Thermoelectric Generator Voltage Test, Current Flow Test and the Power Generated Test by using Refrigerator as the main source of energy generation with temperature difference as its source. 


\subsection{Refrigerator Temperature Testing}

Objective: The purpose of this test is to determine how often the temperature changes with a certain hour and the corresponding hours. And to monitor the change in temperature does the refrigerator produce in the cold and hot side.Test Set-Up: The test will be done during the operation of the project. As the system or the mechanism acts during the processing stage. It will be measured the amount of temperature specifically the cold and hot part in a certain hour and the succeeding hours.

Methodology: Measuring of temperature will be done in different number of test in succeeding hours.

\begin{tabular}{|c|c|c|}
\hline $\begin{array}{c}\text { Time } \\
\text { Duration }\end{array}$ & $\begin{array}{l}\text { Temperature } \\
\text { in Hot }\end{array}$ & $\begin{array}{l}\text { Temperature } \\
\text { in Cold }\end{array}$ \\
\hline after 1 hour & 35 & 29 \\
\hline $\begin{array}{ll}\text { after } & 2 \\
\text { hours } & \end{array}$ & 37 & 20 \\
\hline $\begin{array}{ll}\text { after } & 3 \\
\text { hours } & \end{array}$ & 43 & 27 \\
\hline $\begin{array}{ll}\text { after } & 4 \\
\text { hours } & \end{array}$ & 37 & 23 \\
\hline
\end{tabular}

TABLE 1: Results in Time duration of different temperature

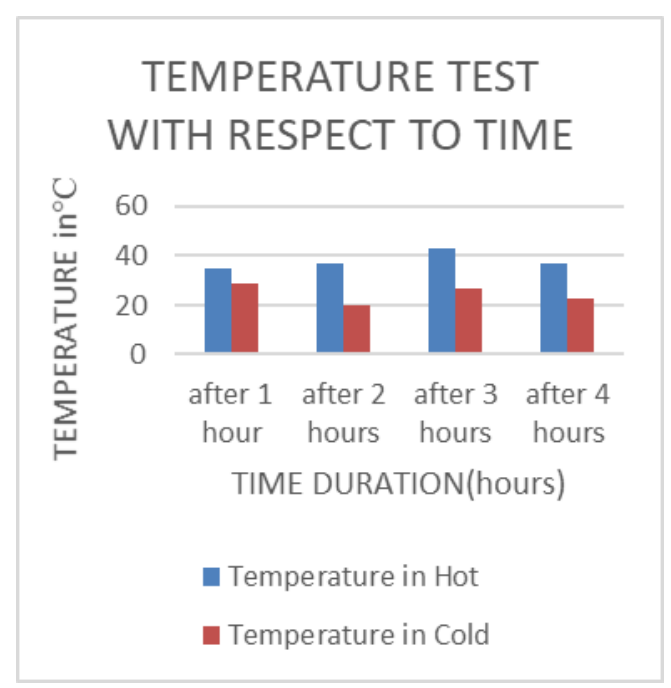

FIGURE 1: Temperature testing with respect to time of the system

It shows in the figure that the temperature is not totally varying when it is operating. But due to some factors like the opening and closing of refrigerator; that factors affects the temperature because the group determines that the refrigerator maintain a certain temperature in the cold side when conducting.

When the refrigerator is open, there is a certain change in temperature because hot air enters the refrigerator and affects the temperature. Therefore, the refrigerator starts to conduct and produces a certain low temperature for the cold part and hot for its hot part.

\subsection{Thermoelectric Generator voltage test}

Objective: The purpose of this test is to identify the different voltages that can be measured with the Thermoelectric Generator with respect to different temperatures.
Test Set-up: The test will be performed when actual usage of the Thermoelectric Generator. It will be measured the voltage using a voltmeter using different temperature read by a thermometer gun after the conversion in the circuit is done.

Methodology: The measurement of voltage will be done using 20 test with different temperature of hot and cold.

\begin{tabular}{|c|c|c|c|}
\hline \multicolumn{3}{|c|}{ TEMPERATURE (Celsius) } & \multirow{2}{*}{$\begin{array}{c}\text { VOLTAGE } \\
\text { OUTPUT } \\
(\mathrm{V})\end{array}$} \\
\hline COLD & HOT & DIFFERENCE & \\
\hline 23.5 & 37.5 & 14 & 5.42 \\
\hline 26.5 & 42 & 15.5 & 5.45 \\
\hline 25 & 43 & 18 & 5.65 \\
\hline 27 & 46.2 & 19.2 & 5.66 \\
\hline 18 & 38 & 20 & 5.73 \\
\hline 22 & 42 & 20 & 5.78 \\
\hline 19.5 & 40.5 & 21 & 5.81 \\
\hline 4.5 & 26 & 21.5 & 5.82 \\
\hline 21.5 & 43.5 & 22 & 5.84 \\
\hline 23 & 45 & 22 & 5.84 \\
\hline 20.5 & 43 & 22.5 & 5.91 \\
\hline 7 & 30 & 23 & 5.91 \\
\hline 18.5 & 42 & 23.5 & 5.93 \\
\hline 21 & 45 & 24 & 5.96 \\
\hline 21 & 47 & 26 & 5.96 \\
\hline 19.5 & 49 & 29.5 & 5.96 \\
\hline 12 & 43 & 31 & 5.98 \\
\hline 6.5 & 43 & 36.5 & 6.03 \\
\hline 3.5 & 43 & 39.5 & 6.1 \\
\hline 0.5 & 42 & 41.5 & 6.1 \\
\hline
\end{tabular}

TABLE 2: Results in Voltage testing on Thermoelectric Generator.

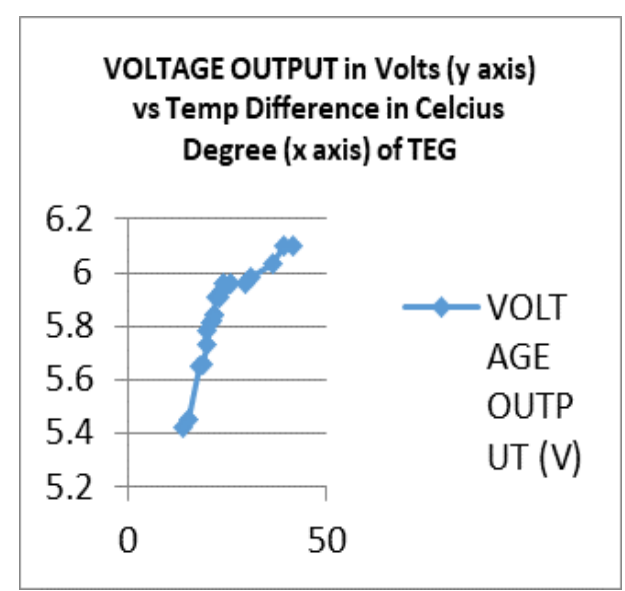

FIGURE 2: The figure shows the different temperature produces different voltages.

In the figure it illustrates that different temperature produces different voltages. And the bigger the potential difference the larger the voltages 


\subsection{Current Flow test}

Objective: The purpose of this test is to recognize the current flowing in the thermoelectric generator in the system.

Test Set-Up: This test will measure different currents with different temperature. The proponent used different temperature sandwich with the thermoelectric generator. The Ammeter was series with the Converter Circuit and a load of 10W resistor. Methodology: The current test will be measured with different temperature connected to a load of $10 \mathrm{~W}$ resistor. The assessment will have:

\begin{tabular}{|c|c|c|c|}
\hline \multicolumn{3}{|c|}{ TEMPERATURE (Celsius) } & \multirow{2}{*}{$\begin{array}{c}\text { CURRENT } \\
\text { OUTPUT } \\
(\mathrm{mA})\end{array}$} \\
\hline COLD & HOT & DIFFERENCE & \\
\hline 23.5 & 37.5 & 14 & 0.73 \\
\hline 26.5 & 42 & 15.5 & 0.75 \\
\hline 25 & 43 & 18 & 0.76 \\
\hline 27 & 46.2 & 19.2 & 0.76 \\
\hline 18 & 38 & 20 & 0.76 \\
\hline 22 & 42 & 20 & 0.76 \\
\hline 19.5 & 40.5 & 21 & 0.76 \\
\hline 4.5 & 26 & 21.5 & 0.77 \\
\hline 21.5 & 43.5 & 22 & 0.77 \\
\hline 23 & 45 & 22 & 0.78 \\
\hline 20.5 & 43 & 22.5 & 0.79 \\
\hline 7 & 30 & 23 & 0.81 \\
\hline 18.5 & 42 & 23.5 & 0.81 \\
\hline 21 & 45 & 24 & 0.82 \\
\hline 21 & 47 & 26 & 0.82 \\
\hline 19.5 & 49 & 29.5 & 0.83 \\
\hline 12 & 43 & 31 & 0.83 \\
\hline 6.5 & 43 & 36.5 & 0.83 \\
\hline 3.5 & 43 & 39.5 & 0.84 \\
\hline 0.5 & 42 & 41.5 & 0.85 \\
\hline
\end{tabular}

Table 3: The data gathered using an ammeter connected to the Circuit Converter to a load of $10 \mathrm{~W}$ resistor

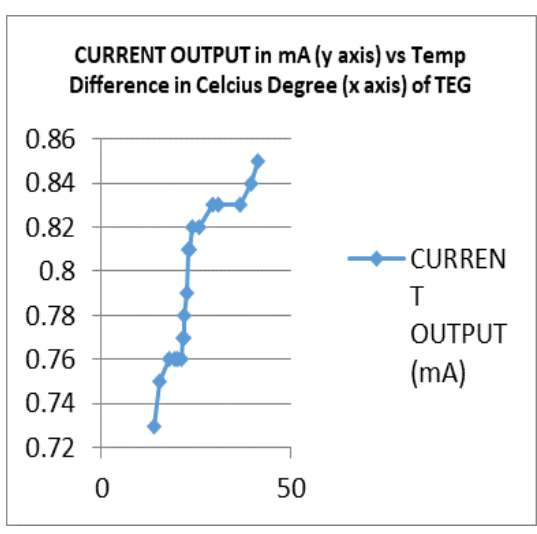

FIGURE 3: The figures shows current flow of the thermoelectric generator in different potential difference.

Based on the illustration above the figure indicates the current flow of the thermoelectric generator during the operation. Therefore, the current flow of the circuit is based depending on the change of temperature. Simply means that the current is directly proportional to the change in temperature or as the temperature difference increases the current flow will increase also. But in an ideal way, current must be constant during operation to provide a better output voltage.

\subsection{Power Generated Test}

Objective: The purpose of this test is to recognize the power generated in the thermoelectric generator in the system. Reference: K. Matsubara, in Twenty-first International Conference on Thermoelectrics, Proceedings, ICT'02, 418 (2002). Test Set-Up: This test will measure different power with different temperature. The proponent use different temperature connected to the circuit converter. From the figures given above the proponent use the conventional way in calculating the power. Using the formula $\mathrm{P}=\mathrm{IV}$ Methodology: The current test will be compute through the results given on the table 5.2 and 5.3. The assessment will have 20 different test.

\begin{tabular}{|r|r|r|r|}
\hline \multicolumn{2}{|r|}{ TEMPERATURE (Celsius) } & POWER \\
\cline { 1 - 3 } COLD & HOT & DIFFERENCE & (mW) \\
\hline 23.5 & 37.5 & 14 & 525 \\
\hline 26.5 & 42 & 15.5 & 651 \\
\hline 25 & 43 & 18 & 774 \\
\hline 27 & 46.2 & 19.2 & 887.04 \\
\hline 18 & 38 & 20 & 760 \\
\hline 22 & 42 & 20 & 840 \\
\hline 19.5 & 40.5 & 21 & 850.5 \\
\hline 4.5 & 26 & 21.5 & 559 \\
\hline 21.5 & 43.5 & 22 & 957 \\
\hline 23 & 45 & 22 & 990 \\
\hline 20.5 & 43 & 22.5 & 967.5 \\
\hline 7 & 30 & 23 & 690 \\
\hline 18.5 & 42 & 23.5 & 987 \\
\hline 21 & 45 & 24 & 1080 \\
\hline 21 & 47 & 26 & 1222 \\
\hline 19.5 & 49 & 29.5 & 1445.5 \\
\hline 12 & 43 & 31 & 1333 \\
\hline 6.5 & 43 & 36.5 & 1569.5 \\
\hline 3.5 & 43 & 39.5 & 1698.5 \\
\hline 0.5 & 42 & 41.5 & 1743 \\
\hline
\end{tabular}

Table 4: The results coming from the computed value of table 5 and 6

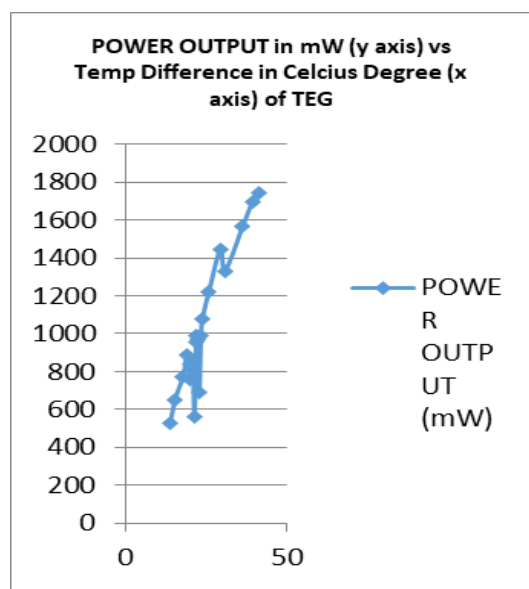

FIGURE 4: The figures power generated of the thermoelectric generator in different potential difference. 
Based on the illustration above the figure indicates the power generated of the thermoelectric generator. The proponent concludes that if the temperature difference of hot and cold is extreme, higher power can be gain.

\subsection{DURATION OF CHARGING DEPENDING ON THE CURRENT FLOW}

\begin{tabular}{|c|c|}
\hline CURRENT & $\begin{array}{c}\text { CHARGING DURATION OF } \\
\text { BATTERY }\end{array}$ \\
\hline $0.1 \mathrm{~mA}$ & 12.5 hours \\
\hline $0.3 \mathrm{~mA}$ & 4.17 hours \\
\hline $0.6 \mathrm{~mA}$ & 2.08 hours \\
\hline $1.29 \mathrm{~mA}$ & 0.968 hours \\
\hline $1.5 \mathrm{~mA}$ & 0.833 hours \\
\hline
\end{tabular}

Table 5

\section{COMPUTATION:}

1. $(0.1 \mathrm{~mA} \times 3600)=0.36 \mathrm{~A}$ $4.5 \mathrm{AH} / 0.36 \mathrm{~A}=12.5$ hours

2. $(0.3 \mathrm{~mA} \times 3600)=1.08 \mathrm{~A}$ $4.5 \mathrm{AH} / 1.08 \mathrm{~A}=4.17$ hours

3. $(0.6 \mathrm{~mA} \times 3600)=2.16 \mathrm{~A}$ $4.5 \mathrm{AH} / 2.16 \mathrm{~A}=2.08$ hours

4. $(1.29 \mathrm{~mA} \times 3600)=4.64 \mathrm{~A}$ 4.5AH/4.64A $=0.968$ hours

5. $(1.5 \mathrm{~mA} \times 3600)=5.4 \mathrm{~A}$ $4.5 \mathrm{AH} / 5.4 \mathrm{~A}=0.833$ hours

The testing allows the proponent to compute for the charging duration of the battery from the harnessed energy of the Thermo-Electric Generator. The system does not have consistency in producing voltage and current. The reason behind the inconsistency of the energy harvested is because hot and cold part of the refrigerator. With the acquired testing, current is considered constant. It can be conclude based on the testing that the higher the value of the current, the shorter the duration of the battery to charge.

\section{V.CONCLUSIONS AND RECOMMENDATIONS}

\section{CONCLUSION}

The system provides a charging station that gets its energy from the temperature difference (Wasted Energy) that can support low-powered devices specifically cell phones. Energy was collected using Thermo-Electric Generators that acts as a harnessing device from the temperature gradient coming from the refrigerator's compressor heat and inside coldness. The output voltage tested by the proponent is ranging from 4- 5.5 volts. Inconsistent output voltage because of uncontrollable temperature variations from the refrigerator. Current measured and harvested also ranges from $.3 \mathrm{~mA}$ to $1.5 \mathrm{~mA}$ which means current ratings also differ based on the output voltage because current and voltage are proportional to each other. This leads to the storage of the energy in the battery bank, which is a 12-volt deep cycle lead acid battery. The stored energy will then be used in the charging station. This system will serve as a new technology for the people to use with convenience and at ease. The system is rated one peso per two minutes and it is a multi-coin. It is programmed to increment every time a coin was dropped and it also has a button for cancellation when you will leave and still the timer is still counting, for energy conservation purposes. It is easy to use because it has an instruction flashing on the LCD. By just the wasted or neglected temperature difference, the proponent has built a system that supports low-powered devices (Cell phones). Different phases, researches, interviews, studies and brainstorming were used to make the system possible. Unlike Solar Panels, Thermo-Electric Generates lesser energy. But nonetheless, this study only focuses on new harvesting circuits. Not competing with other harvesting circuit but introducing new harvester that make the people aware and for new ideas by means of our system.

The wasted energy coming from the neglected heat of the refrigerator was being conserved and boosts to use it in different applications. One of these applications is the charging station. The potential difference of the cold and hot part of the refrigerator was being conserved and converts to another form of energy useable to charge cell phone. Based on the experiments and test performed by the researchers; they come out with results of the wasted heat energy. The output mean voltage for the TEG1 is $30.79 \mathrm{mV}$ and for TEG2 is $26.98 \mathrm{mV}$ and for the current for TEG1=TEG2 $=0.02 \mathrm{~mA}$ and for the output power are for TEG1 $=0.6158 \mathrm{uW}$ and for TEG2 $=0.5396 \mathrm{uW}$. The total mean parameters for the output system are the following: mean voltage $=5.82 \mathrm{~V}$, the mean current $=0.8695 \mathrm{~mA}$, and the mean power output $=$ $4.60165 \mathrm{~mW}$.

The proponent used the said appliance because of its 24/7 non-stop operation compare to the other appliance with a cool and hot part. Another consideration is that most consumers or household has a refrigerator rather than an air-conditioner and water dispenser. Another thing is that it is widely used in the society and particularly in the market and other grocery stores. Specific voltage is $7 \mathrm{~V}$ and the current rating is $1.3 \mathrm{~A}$. The total power consumed by the whole system is $0.26 \mathrm{~mW}$.

\section{Recommendations and Future Directives}

For implementation, development and further study of the system, the proponent would like to recommend different aspects or directives for the system to be improved. First thing is that future researchers can use another appliance aside from refrigerator like water dispenser, Air-conditioners, cars and other objects that has a cold and hot temperature. It is also more efficient if several Thermo-Electric Generators would be added for faster harnessing of energy. System's output has only a ratio of one is to one, therefore, the proponent recommend to change the system's output ratio or several servers. You can also partner different harvesting energy material like solar panel and etc. with Thermo-Electric Generator for higher harnessed energy that can support not only low-powered device but also other high-powered devices. Also a recommendation from one of the panelist is to make the system "Refrigerator with built in charger" that the system would only act as one attached in the refrigerator. On the other hand, the holes made by the proponent on the prototype were large because of the tube used. 
For the hole, the proponent thought of other way on how to install holes. Use smaller diameter of tubes like PVC pipes then the opening would be the larger part of the tube for the Thermo-Electric Generator's size. The smaller diameter of the tube, the more coolness received by the Thermo-Electric Generator because of focused flow from the tube to the Cold plate.

\section{REFERENCES}

1. C.P. Henze and N. Mohan, "A digitally controlled ac to dc

2. power conditioner that draws sinusoidal input current", IEEE

3. PowerElectronics Specialists Cqfeerence, 1986, pp. 531-540 distortion and minimised conducted emissions", European

4. Power Electronics Confemn, 1989, pp 457460 "Using SEPIC topology for improving power factor in distributed powex supply systems", Euwpean Power Electnmics Conference, 199 1, pp 304-309

5. J. Klein and M. Nalbant, "Power factor Correction- incentives, standards and techniques". PCM, June 1990, pp 2638-3131

6. J. LoCascio and M. Nalbant, "Active power factor comtion using a flyback topology", PCM, August 1990, pp 10,13,16,17

7. R. Erickson, M. Madigan and S. Singer, "Design of a simple high-power-factor rectifier based on the flyback converter", Applied Power Electronics Conference, 1990, pp. 792-801

8. M. Madigan, R. Enckson and E. Ismail, "Integrated high quality M. Albach, "An ac-dc converter with low mains current J. Sebastih, J. Uceda, J.A. Cobos, J. Arau andR. Lorenzo, rectifier-regulators", $P \sim r$ $\sim \sim 8$ c $t$ ? v nspi cecsi $a \sim i s t s$ Conference, 1992. pp 1043-1051

9. Kwang-Hwa Liu and Yung-Lin Lin, "Current Waveform Distortion In Power Factor Correction Circuits Employing Discontinuous-mode Boost Converters", IEEE Power Electronics Specialists Conference, 1989, pp. 825-829

\section{AUTHORS PROFILE}

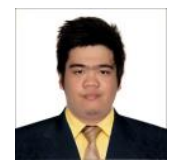

Anthony S. Tolentino is a Licensed Electronics Engineer $\mathrm{He}$ is currently in the final defense of his thesis in his graduate studies in Master of Science in Electronics Engineering at De La Salle University - Manila. Member, Institute of Electronics Engineers of the Philippines. His research works focus mostly in alternative energy systems, green engineering, and integrated circuit design and analysis. 